\title{
O desenvolvimento de competências empreendedoras em alunos do ensino médio a partir da utilização de metodologias diferenciadas e ferramentas tecnológicas
}

\author{
The development of entrepreneurial skills in high school students using different \\ methodologies and technological tools
}

\begin{abstract}
Anderson Daniel Stochero (i) https://orcid.org/0000-0002-4481-6605 Universidade Regional Integrada do Alto Uruguai e das Missões - URI E-mail: anderson stochero@yahoo.com.br
\end{abstract}

Rozelaine de Fatima Franzin (1)https://orcid.org/0000-0001-7204-5281 Universidade Regional Integrada do Alto Uruguai e das Missões - URI E-mail: rozelaine@san.uri.br

\begin{abstract}
Resumo
Discutir sobre empreendedorismo é imprescindível e impacta diretamente na vida em sociedade. Assim, a realização deste trabalho tem por objetivo apresentar o desenvolvimento de um estudo que busca contribuir com a disseminação da cultura empreendedora no ambiente escolar. A metodologia empregada se caracteriza como aplicada de abordagem qualitativa, seu objetivo é exploratório apoiado nos procedimentos técnicos de pesquisa-ação e pesquisa participante. Após o levantamento bibliográfico, foram realizados encontros temáticos com base nos conceitos e características empreendedoras, auxiliados pela utilização de metodologias ativas e ferramentas tecnológicas. Os encontros contribuíram para o desenvolvimento de um jogo computacional denominado "Trilha Empreendedora", o qual se apresenta como uma ferramenta auxiliar no ensino de empreendedorismo. É importante destacar que as características empreendedoras ultrapassam as barreiras organizacionais, possibilitando uma visão abrangente e diferenciada sobre o ambiente. Nesse sentido, o ensino de empreendedorismo também se estabelece como um potencial aliado na formação escolar e social dos alunos, pois permite a identificação e transformação de ideias em oportunidades, sonhos em realidade, metas e objetivos em resultados concretos, boas ideias em produtos e serviços inovadores. A partir da realização desse estudo, pôde-se observar o notável avanço na percepção dos alunos em relação ao tema proposto, contribuindo de maneira efetiva na disseminação da cultura empreendedora nos ambientes escolares com o auxílio de ferramentas tecnológicas.
\end{abstract}

Palavras-chave: Empreendedorismo. Metodologias ativas. Ferramentas Tecnológicas.

\begin{abstract}
Discussing entrepreneurship is essential and has a direct impact on life in society. Thus, this work aims to present the development of a study that seeks to contribute to the dissemination of entrepreneurial culture in the school environment. The methodology used is characterized as an applied qualitative approach, its objective is exploratory supported by technical procedures of action research and participant research. After the bibliographical survey, thematic meetings were held based on entrepreneurial concepts and characteristics, aided by the use of active methodologies and technological tools. The meetings contributed to the development of a computer game called
\end{abstract}


"Entrepreneurial Trail", which is presented as an auxiliary tool in teaching entrepreneurship. It is important to highlight that entrepreneurial characteristics go beyond organizational barriers, enabling a comprehensive and differentiated view of the environment. In this sense, the teaching of entrepreneurship is also established as a potential ally in the educational and social education of students, as it allows the identification and transformation of ideas into opportunities, dreams into reality, goals and objectives into concrete results, good ideas in products and services innovative. From the completion of this study, it was possible to observe the remarkable advance in the students' perception regarding the proposed theme, effectively contributing to the dissemination of the entrepreneurial culture in school environments with the help of technological tools.

Keywords: Entrepreneurship. Active methodologies. Technological Tools.

\section{Introdução}

O empreendedorismo se apresenta como um tema imprescindível de ser analisado e discutido em todo e qualquer ambiente, tanto formal quanto informal, pois é a partir dele que se tem a possibilidade de melhorar a qualidade de vida dos indivíduos e consequentemente da sociedade como um todo.

Quando alguma pessoa decide empreender ela está contribuindo para o desenvolvimento local e regional, promovendo mais empregos, movimentando a economia, inovando na oferta de produtos e serviços, encontrando maneiras de contribuir para o crescimento do ambiente no qual está inserido, além de promover soluções para problemas urgentes.

Diante disso, faz-se necessário pensar nos meios possíveis de incentivo e disseminação da cultura empreendedora, tendo ciência de que o espaço escolar se apresenta como um potencial aliado para aproximar os jovens do empreendedorismo, possibilitando a eles uma nova visão de mundo e contribuindo de maneira positiva no processo de formação desses estudantes.

O estudo se propõe a fomentar o desenvolvimento de características empreendedoras, por meio do ensino de conceitos relacionados ao empreendedorismo para jovens do Ensino Médio, auxiliado pela utilização de ferramentas tecnológicas e metodologias de ensino diferenciadas, visando assim, contribuir de forma efetiva na capacidade dos indivíduos de empreender nas mais diversas áreas do conhecimento e de conviver em sociedade.

O desenvolvimento deste estudo se deu, em um primeiro momento, sob o caráter bibliográfico, fazendo um oportuno levantamento sobre os conceitos relacionados ao empreendedorismo, suas potencialidades no ensino, o desenvolvimento de práticas educacionais no processo de ensino e aprendizagem e sobre a utilização da tecnologia como ferramenta auxiliar de ensino. Após essa etapa, foi proposta a realização de intervenções, em uma escola pública federal, com alunos do ensino médio, e com um grupo de voluntários que participaram de dez encontros temáticos, aprimorando sua visão sobre as potencialidades do empreendedorismo e do desenvolvimento do perfil empreendedor.

A partir dos encontros realizados e dos dados levantados, foi possível desenvolver um jogo computacional, com o auxílio da plataforma Construct 3, denominado "Trilha Empreendedora", o qual tem por finalidade contribuir com o processo de ensino e aprendizagem sobre os conceitos e características empreendedoras. 


\section{Empreendedorismo e o desenvolvimento de características empreendedoras no ambiente escolar}

O empreendedorismo se apresenta como uma área de grande relevância no atual contexto global, um elemento com significativa participação nos processos de desenvolvimento econômico, social e cultural de todo e qualquer ambiente, e, assim, a partir desta visão, o tema tem sido alvo de estudos e investigações nas últimas décadas.

Nesse sentido, se faz pertinente destacar o estudo de Pereira Júnior (2020), o qual, buscou definir um modelo conceitual denominado "background do empreendedor" para traçar o perfil empreendedor. Este pode ser analisado por diversos aspectos, dentre eles familiares, como a estrutura, a presença de um empreendedor na família, e também estímulos ou desestímulos a empreender, elementos que acabam impactando na definição deste perfil. Outro ponto destacado é o lugar de nascimento e criação, o qual impacta culturalmente na propensão ao empreender, nas oportunidades de trabalho além de implicar em aspectos legais como barreiras ou facilitadores ao empreendedorismo. Há também os aspectos de educação formal ao estímulo de empreender. Destacam-se aspectos sociodemográficos, como: mobilidade e gênero. Aspectos de atividade profissional, como ter trabalhado antes de empreender, a experiência com alguma atividade, gerando know-how; e experiência negativa com chefes anteriores. Também, aspectos de fé e/ou religião: professar uma religião; e crer na direção e ajuda divina para empreender.

Pode-se perceber as os inúmeros aspectos que podem compor a formação de um perfil empreendedor, variáveis que podem estimular ou desestimular o jovem a lançar-se no mundo do empreendedorismo. E, desta forma, é possível perceber que o empreendedorismo está estritamente ligado a características como iniciativa, capacidade de inovação e identificação de oportunidades. Assim, se faz pertinente, também, apresentar quem é o empreendedor.

Para Dolabela (2006), o empreendedor é aquele que se caracteriza como um ser social, um produto do ambiente no qual está inserido, ou seja, é um indivíduo que tem em seu entorno um espaço voltado para a inovação e para o empreendedorismo, sendo ele capaz de identificar esses elementos como algo positivo e consequentemente ser impelido a desenvolver as características pertinentes.

Para Chiavenato (2012) o perfil empreendedor se destaca por três características principais: a necessidade de realização, a disposição para assumir riscos e a autoconfiança. Baseando-se nesses elementos, é possível apresentar inúmeras outras características empreendedoras, de forma que diversos autores acabam por classificá-las de formas distintas, conforme apresentado no quadro 1:

Quadro 1: Características empreendedoras

\begin{tabular}{|c|c|c|c|c|}
\hline $\begin{array}{l}\text { DORNELAS } \\
(2017)\end{array}$ & $\begin{array}{l}\text { CAUTHIER; MACEDO; LABIAK } \\
(2010)\end{array}$ & $\begin{array}{l}\text { HASHIMOTO } \\
\text { (2009) }\end{array}$ & $\begin{array}{l}\text { SALIM E SILVA } \\
(2010)\end{array}$ & $\begin{array}{l}\text { CHIAVENATO } \\
(2012)\end{array}$ \\
\hline $\begin{array}{l}\text { - São visionários } \\
\text { - Sabem tomar } \\
\text { decisões } \\
\text { - São indivíduos que } \\
\text { fazem a diferença }\end{array}$ & $\begin{array}{l}\text { - Possui vontade de vencer } \\
\text { - Gosta de liderar equipes e sentir-se como } \\
\text { um líder } \\
\text { - Doa-se com amor ao seu } \\
\text { empreendimento } \\
\text { - É obstinado, determinado }\end{array}$ & $\begin{array}{l}\text { - Superação } \\
\text { - Criatividade } \\
\text { - Iniciativa }\end{array}$ & $\begin{array}{l}\text { - Adotam clara atitude } \\
\text { proativa de } \\
\text { observação da } \\
\text { realidade, que os leva } \\
\text { a ter uma boa }\end{array}$ & $\begin{array}{l}\text { - Consegue fazer } \\
\text { as coisas } \\
\text { acontecerem }\end{array}$ \\
\hline
\end{tabular}




\begin{tabular}{|c|c|c|c|c|}
\hline $\begin{array}{l}\text { - Sabem explorar ao } \\
\text { máximo } \\
\text { oportunidades } \\
\text { - São determinados e } \\
\text { dinâmicos } \\
\text { - São dedicados } \\
\text { - São otimistas e } \\
\text { apaixonados pelo } \\
\text { que fazem } \\
\text { - São independentes } \\
\text { e constroem o } \\
\text { próprio destino } \\
\text { - Ficam ricos } \\
\text { - São líderes e } \\
\text { formadores de } \\
\text { equipes } \\
\text { - São bem } \\
\text { relacionados } \\
\text { (networking) } \\
\text { - São organizados } \\
\text { - Planejam, } \\
\text { planejam, planejam } \\
\text { - Possuem } \\
\text { conhecimento } \\
\text { - Assumem riscos } \\
\text { calculados } \\
\text { - Criam valor para a } \\
\text { sociedade }\end{array}$ & $\begin{array}{l}\text { - Eterno insatisfeito... Está sempre } \\
\text { querendo mais } \\
\text { - Irrequieto } \\
\text { - Busca sempre novos desafios } \\
\text { - Focado } \\
\text { - Trabalha em equipe } \\
\text { - Extrai o melhor de cada membro da } \\
\text { equipe } \\
\text { - Sabe lidar com recursos financeiros e } \\
\text { humanos } \\
\text { - Consegue observar uma oportunidade } \\
\text { - Aproveita as oportunidades observadas } \\
\text { - Sabe construir uma rede de parceiros } \\
\text { - Usa com maestria a sua criatividade } \\
\text { - Está conectado a tendências globais } \\
\text { - Está aberto às mudanças e se desapega } \\
\text { de ideias antigas } \\
\text { - Acredita nas novas ideias } \\
\text { - Tem elevada autoestima } \\
\text { - Compartilha conhecimentos com sua } \\
\text { equipe } \\
\text { - Distribui recursos aos membros da equipe } \\
\text { - Possui princípios éticos e morais } \\
\text { - Identificam oportunidades onde muitos } \\
\text { enxergam problemas ou riscos } \\
\text { - É um ser criativo } \\
\text { - Possui rapidez na tomada de decisões e } \\
\text { ações } \\
\text { - Busca a liberdade e a felicidade }\end{array}$ & $\begin{array}{l}\text { - Energia } \\
\text { - Valor } \\
\text { - } \\
\text { Compromisso } \\
\text { - Risco }\end{array}$ & $\begin{array}{l}\text { percepção de } \\
\text { oportunidade } \\
\text { - São capacitados } \\
\text { para capturar e avaliar } \\
\text { oportunidades e, a } \\
\text { partir de suas ideias, } \\
\text { desenvolver planos } \\
\text { para realizar seus } \\
\text { objetivos } \\
\text { - Desenvolvem } \\
\text { habilidades para obter } \\
\text { apoio de } \\
\text { colaboradores e de } \\
\text { financiadores para } \\
\text { seus } \\
\text { empreendimentos } \\
\text { - São habituados a } \\
\text { tomar decisões } \\
\text { - Buscam } \\
\text { incessantemente criar } \\
\text { valor para a } \\
\text { sociedade através de } \\
\text { seus } \\
\text { empreendimentos }\end{array}$ & $\begin{array}{l}\text { - Dotado de } \\
\text { sensibilidade para } \\
\text { os negócios } \\
\text { - Tino financeiro } \\
\text { - Capacidade de } \\
\text { identificar e } \\
\text { aproveitar } \\
\text { oportunidades } \\
\text { - Transforma ideias } \\
\text { em realidade } \\
\text { - Criatividade } \\
\text { - Alto nível de } \\
\text { energia } \\
\text { - Imaginação e } \\
\text { perseverança } \\
\text { - Liderança e } \\
\text { sabem trabalhar } \\
\text { em equipe }\end{array}$ \\
\hline
\end{tabular}

Fonte: autores (2020).

Apesar de cada autor possuir uma visão diferenciada sobre as características mais relevantes na constituição de um perfil empreendedor, pode-se perceber que, em grande parte, muitas acabam por se apresentar de maneira recorrente, como, por exemplo, a criatividade, a capacidade de enfrentar riscos e a autoconfiança. Assim como destacado pelos autores Fernandes et. al. (2020), os quais enfatizam que na literatura que os comportamentos e atitudes dos empreendedores se apresentam, muitas vezes como semelhantes.

As características apresentadas levam a uma reflexão, que há muito tempo foi tema de estudos e discussões, qual seja: por um longo período o empreendedor foi visto como portador de uma configuração genética diferenciada, ou melhor, os empreendedores seriam seres singulares e beneficiados por herdarem tais características, porém essa visão se configurou como errônea acerca do perfil empreendedor (DOLABELA, 2015).

Além disso, o mesmo autor afirma em sua obra que o empreendedor precisa principalmente de autoconhecimento e, a partir disso, poderá construir complementaridades, ou seja, procurar em outros indivíduos os elementos e características que não possui.

Fernandes et. al. (2020) enfatizam ainda que existem outros aspectos capazes de influenciar o comportamento empreendedor, dentre eles estão as questões e diferenças culturais, sociais e de mercado, as quais podem contribuir de maneira positiva ou negativa na propensão de empreender do indivíduo. Ressaltam ainda que o empreendedorismo se tornou muito mais do que apenas a criação de empresas, estando relacionado a outros aspectos como criatividade, motivação, assunção a riscos, redes de relacionamento, pro atividade, liderança, necessidade de realização e criação de valor. 
O ensino de empreendedorismo se apresenta como potencial aliado na formação escolar e social dos indivíduos, pois, de acordo com Dornelas (2017), o conceito empreendedor pode ser ensinado e entendido por qualquer pessoa, permitindo a capacitação do indivíduo, desenvolvendo habilidades técnicas, gerenciais e características pessoais. Desta forma, dentre as habilidades técnicas pode-se destacar o saber escrever, ouvir, captar informações, ter boa oratória, organização, habilidade de liderança e trabalho em equipe, além de possuir know-how técnico na área de atuação. Em relação as habilidades gerenciais, pode-se destacar as áreas de criação, desenvolvimento e gerenciamento de uma nova empresa, tomada de decisão, controle das ações empresariais e ser um bom negociador. Por fim, apresentam-se as características pessoais, tais como ser disciplinado, assumir riscos, ser inovador, ser orientado a mudanças, ser persistente e ser um líder visionário.

Segundo Rojas, Monich e Lezana (2010), muitos autores afirmam que, para obter maior sucesso no desenvolvimento de habilidades e competências empreendedoras, o ensino deve começar cedo. A importância do desenvolvimento precoce do empreendedor também é destacada por Santos e Pellin (2008) apud Rojas, Monich e Lezana (2010), os quais demonstram que, a partir de benchmark realizado na ONG Junior Achivement, a aprendizagem deve começar no ensino fundamental e seguir até a graduação.

Desta forma, apresenta-se a Pedagogia Empreendedora como uma metodologia de ensino de empreendedorismo para a Educação Básica, proposta por Fernando Dolabela, a qual pretende sensibilizar jovens para estimular sua capacidade de escolha, sem influenciar as suas decisões, preparando-o para as suas próprias opções. Essa metodologia trata o empreendedorismo como uma forma de ser e não somente de fazer, transportando o conceito que nasceu na empresa para todas as áreas da atividade humana. Ela está vinculada a tecnologias de desenvolvimento local, sustentável, por isso tem como alvo não só o indivíduo, mas a comunidade, o que se torna possível através da união entre o empreendedorismo e a educação básica (DOLABELA, 2008).

Outras ações que também visam o ensino de empreendedorismo para jovens são realizadas pelo professor José Dornelas, o qual, através do Instituto Fazendo Acontecer, fomenta a disseminação do empreendedorismo entre crianças e adolescentes por meio de oficinas extracurriculares. $O$ foco das oficinas reside na aquisição de competências empreendedoras que são ensinadas aos alunos com ludicidade e muita prática. $O$ que se procura é moldar as reações discentes com relação aos problemas corriqueiros do percurso empreendedor, como a falta de tempo e de recursos. Dessa forma, todas as oficinas utilizam desafios oriundos de experiências reais (AVENI; MELLO, 2019).

Lopes, Lima e Nassif (2017) apresentam que a educação para o empreendedorismo é capaz de proporcionar o desenvolvimento de competências importantes para os indivíduos, permitindo que principalmente os jovens estejam mais preparados para outras opções de carreira, e, não somente a de ser empregado em organizações criadas e dirigidas por outros, aumentando as possibilidades e potencialidades de atuação, podendo incluir o autoemprego, o início do próprio negócio e o intraempreendedorismo, ou seja, podem empreender dentro de uma organização, fundar e participar de projetos ou negócios sociais e até mesmo desenvolver perspectivas mais empreendedoras da própria vida e de inserção na sociedade. 
Fernandes et. al. (2019) complementam que o empreendedor normalmente contribui a partir de uma atividade inovadora com o desenvolvimento econômico de uma região a partir da identificação de oportunidades, muitas vezes relacionandose ao desenvolvimento sustentável; inovação, desempenho organizacional.

Assim, os alunos poderão se apropriar dos conceitos trabalhados, tornando-se capazes de desenvolver uma visão abrangente por meio das noções de empreendedorismo, e, por consequência, se preparar para o futuro, para a inserção no mercado de trabalho e para o convívio em sociedade, independentemente da futura área de atuação.

Diante do exposto, faz-se necessário refletir sobre as possibilidades de ensino e aprendizagem de empreendedorismo no ambiente escolar, e, nesta perspectiva, Masseto (2007) destaca que para maximizar o processo de aprendizagem de um aluno é imprescindível aderir a técnicas diferenciadas de ensino, objetivando motivar o jovem para que participe de maneira efetiva, através da proposição, durante as aulas, de atividades dinâmicas, diferenciadas e atrativas, fazendo com que o discente saia da posição passiva de espectador e se torne atuante de fato na construção do conhecimento.

\section{O ensino e a aprendizagem no desenvolvimento de práticas educacionais associadas a utilização da tecnologia como ferramenta auxiliar de ensino}

Ao longo das décadas, o processo de ensino e aprendizagem tem sido analisado a partir de diferentes enfoques objetivando explicá-lo, sendo possível concluir que muitas das abordagens estão diretamente relacionadas com o momento histórico de sua criação e do contexto social na qual estavam inseridas. Desta forma, se torna pertinente ter ciência de que o processo é composto de duas partes: ensinar, que exprime uma atividade, e aprender, que envolve certo grau de realização de uma determinada tarefa com êxito (SANTOS, 2005). Nesse sentido é pertinente adequar-se no tempo e no espaço para melhor desenvolver o processo de ensinar e possibilitar um adequado aprender.

Ferro e Paixão (2017) enfatizam que o ensino necessita de diversos cuidados como planejamento, sistematização e avaliação, se fazendo importante definir objetivos, selecionar conteúdos, especificar estratégias de ensino e recursos adequados, avaliar a aprendizagem do aluno e a eficiência do ensino. O professor exerce a função de criar as condições para que o aluno consiga exercer a sua ação de aprender.

Anastasiou e Alves (2009) apresentam propostas estratégicas passíveis de serem desenvolvidas em sala de aula, como, por exemplo: Aula expositiva dialogada; Estudo de texto; Portfólio; Tempestade cerebral; Mapa conceitual; Estudo dirigido; Lista de discussão por meios informatizados; Solução de problemas; Philips 66; Grupo de verbalização e de observação; Dramatização; Seminário; Estudo de caso; Júri simulado; Simpósio; Painel; Fórum; Oficina (laboratório ou workshop); Estudo do meio; Ensino com pesquisa; Intergrupo - EaD; Estudo de caso - EaD; Leitura estruturada dirigida, de confronto ou sintética - EaD.

Cada estratégia possui um objetivo específico, fomentando operações de pensamento específicas e obtendo resultados otimizados em relação ao proposto, 
visando, assim, contribuir de forma efetiva para o processo de ensino e aprendizagem, fomentando a aprendizagem de forma significativa.

A teoria da aprendizagem significativa desenvolvida por Ausubel propõe que os conhecimentos prévios dos alunos sejam valorizados, pois a aprendizagem se apresenta de forma muito mais significativa quando um novo conteúdo é incorporado ao conhecimento já existente, adquirindo significado a partir desta relação. Quando isto não ocorre, o aprendizado passa a ser mecânico, o novo conteúdo passa a ser armazenado isoladamente, ou por associações arbitrárias, pois, quando o conteúdo escolar aprendido não consegue se conectar com algo já conhecido, são aprendidas sem interagir com conceitos relevantes já existentes. Desta forma, a pessoa acaba por decorar o conteúdo e o esquece com maior rapidez (PELIZZARI et.al, 2002).

Diante do exposto, pode-se perceber o quão necessário é ao docente valer-se da utilização de metodologias que possibilitem um processo de aprendizagem mais efetivo, criando condições favoráveis ao aprendizado. Conforme Moreira, Ludovico e Karolesky (2018), há uma necessidade de ressignificar a aprendizagem, se possível vislumbrar a presença de novas metodologias de ensino, principalmente as identificadas como metodologias ativas, as quais possuem como objetivo principal despertar o protagonismo no discente, incentivando-o a produzir seu próprio conhecimento, auxiliado pelos docentes nesse processo. Assim, tanto discentes quanto docentes podem ser identificados como aprendentes, ou seja, através de trocas nesse processo, todos ensinam e aprendem de maneira coletiva.

Atualmente, vive-se uma nova revolução, desta vez sob um viés tecnológico, que conduz a uma nova era, a Era Digital. O impacto das novas tecnologias implica diretamente no cotidiano de todos os indivíduos, interferindo na velocidade da disseminação de informações e no ritmo, cada vez mais acelerado, do processo de desenvolvimento tecnológico (GABRIEL, 2013).

Kampff (2009) enfatiza que muitas tecnologias já estão incorporadas no cotidiano das pessoas e acabam, por muitas vezes, passando despercebidas. Quando alguma se faz notável passa a ser classificada como uma "nova tecnologia". Geralmente vista com receio, tendo seu uso um futuro duvidoso, pois, o que será feito com ela é que irá determinar sua finalidade principal.

Contudo, cabe ao usuário determinar se a sua finalidade será positiva ou negativa perante a sociedade. Assim, é necessário refletir sobre qual a utilização que se deseja para cada "nova tecnologia", e, para isso, é importante conhecer e optar pelo uso e abordagens mais adequadas.

Desta forma, é necessário que os professores se apropriem cada vez mais das novas tecnologias e as introduzam na sua prática docente. Porém, para que isso se torne factível é imprescindível que haja uma mudança significativa do processo educacional, o que leva a uma profunda reflexão sobre o que vem a ser trabalhar com tecnologias na educação, pois a tecnologia por si só não é capaz de mudar a prática docente. Diversos são os recursos digitais para utilização no contexto escolar, que vão de simples aplicativos para gravação de podcast, apresentações interativas e escrita digital, a recursos mais complexos que exigem um conhecimento maior, como a utilização de plataformas multifuncionais de última geração (MOREIRA, LUDOVICO, KAROLESKY, 2018). 
Diante de tantas tecnologias de informação e comunicação existentes e passíveis de serem utilizadas no ambiente escolar, os jogos se apresentam como uma ferramenta complementar, capazes de agregar a ludicidade ao conteúdo trabalhado em sala de aula, permitindo a integração e cooperação entre os jovens e fomentando o convívio social.

A partir dessas perspectivas, tem-se os jogos educativos como uma possibilidade viável para que o aluno possa aprender de forma natural, prazerosa e dinâmica, desafiando os jovens e instigando a buscar conhecimento, além de possibilitar um maior envolvimento social entre os alunos, contribuindo também para o estabelecimento de conceitos éticos, de solidariedade, de regras, de trabalho em grupo, de respeito mútuo (NICOLETTI; GUERRA FILHO, 2004).

No que tange aos jogos educativos, pode-se abordar os elementos relacionados à gamificação, que por definição de Vianna et al. (2013) corresponde ao uso de mecanismos de jogos orientados ao objetivo de resolver problemas práticos ou de despertar engajamento entre um público específico. Alves (2015) ressalta que a gamificação consiste no uso de elementos de jogos e de técnicas de design de jogos em contextos diferentes. E, de acordo com Signori e Guimarães (2016), possui o intuito de aumentar o engajamento dos usuários com os sistemas, consiste em uma série de técnicas, que têm se mostrado uma alternativa interessante na busca por fortalecer a relação entre consumidores e um determinado produto e/ou serviço.

Quando voltada para a área do ensino e aprendizagem, esse tema se apresenta com um amplo potencial a ser considerado e explorado. Atualmente, as pessoas estão cada vez mais presentes nos ambientes em que a tecnologia e as mídias digitais se destacam, sendo necessário o desenvolvimento de novas abordagens e estratégias para influenciar os discentes, diante da apatia e desmotivação em relação às metodologias de aprendizagem utilizadas na maioria das instituições de ensino (FARDO, 2013)

Contudo, torna-se necessário salientar que a gamificação não deve ser confundida como apenas jogos, pois ela possui elementos dos jogos (como tipo de conquista, competição, recompensas) adaptados a um contexto específico, fazendo com que se envolvam usuários, clientes ou estudantes em uma determinada área, gerando produto ou experiência de aprendizagem considerada anteriormente entediante ou simplesmente cotidiana, contribuindo então para o maior empenho em sua realização (PRINCE, 2013).

Com frequência cada vez maior, o conjunto de técnicas relacionadas à gamificação têm sido desenvolvidas e aplicadas em diversos contextos, por empresas e entidades de diversos segmentos, como alternativas às abordagens tradicionais, sobretudo no que se refere a encorajar pessoas a adotarem determinados comportamentos, a familiarizarem-se com novas tecnologias, a agilizar seus processos de aprendizado ou de treinamento e a tornar mais agradáveis tarefas consideradas tediosas ou repetitivas.

\section{Percurso metodológico}

A natureza da pesquisa realizada se apresenta como aplicada de abordagem qualitativa. Quanto ao seu objetivo, se caracteriza como uma pesquisa exploratória, 
já os procedimentos técnicos desenvolvidos se estabelecem como pesquisa-ação e pesquisa participante.

A partir dessas definições, faz-se importante destacar as etapas percorridas no desenvolvimento do estudo que tem como objetivo contribuir com o ensino de empreendedorismo e o fomento do perfil empreendedor nos ambientes escolares. Nesta perspectiva, foi proposta a realização de dez encontros temáticos.

O desenvolvimento dos encontros ocorreu nas dependências de uma escola pública federal, em um período de 90 dias, no segundo semestre de 2019. Os participantes se caracterizam como alunos do primeiro ano do ensino médio, totalizando 12 participantes com faixa etária entre 15 e 17 anos.

Antes de iniciar os encontros, foi necessário realizar um levantamento bibliográfico, a fim de se apropriar de conceitos relacionados ao empreendedorismo, suas potencialidades de ensino, o desenvolvimento de práticas educacionais e a utilização de tecnologias no processo de ensino e aprendizagem.

Após o levantamento bibliográfico, foram convidados alunos do primeiro ano do ensino médio para participar dos encontros temáticos, sendo que 16 alunos se candidataram para participar de maneira voluntária e 12 participaram efetivamente.

Com a formação do grupo de voluntários foi possível realizar as etapas posteriores. Inicialmente houve a coleta de dados por meio da aplicação de um questionário, com o objetivo de identificar o conhecimento prévio dos alunos em relação ao tema proposto.

Etapa 1 - Coleta de dados: O método de coleta de dados se estabeleceu a partir da aplicação de um questionário inicial na primeira intervenção realizada com os alunos a fim de verificar os conhecimentos prévios dos participantes referente ao tema empreendedorismo, além de identificar suas expectativas e traçar o perfil do grupo de voluntários.

Com base nas respostas obtidas, foram elaborados os encontros temáticos tendo como base a utilização de metodologias ativas e ferramentas tecnológicas, visando despertar o interesse e promover o engajamento dos participantes.

Etapa 2 - Intervenção: As intervenções, se caracterizaram como encontros, os quais foram divididos em dez momentos, em cada encontro foi trabalhado um conceito específico sobre empreendedorismo, baseado na pesquisa teórica realizada previamente e nos dados coletados no questionário inicial. Os encontros foram baseados principalmente em aulas expositivas e dialogadas fomentando a reflexão, análise e discussão dos temas apresentados, com apoio de ferramentas tecnológicas e metodologias ativas.

Para finalizar, e possibilitar a mensuração da eficácia dos métodos empregados, foi proposta a realização de uma entrevista semiestruturada no último encontro.

Etapa 3 - Entrevista semiestruturada: Posteriormente, após as intervenções, foi realizada uma entrevista semiestruturada, visando desenvolver um comparativo acerca da evolução em relação ao conhecimento do tema abordado, a identificação da sua relação com a vida cotidiana e a relevância do estudo proposto. As entrevistas foram gravadas e transcritas visando corroborar com a avaliação dos resultados. 
Após o desenvolvimento da entrevista semiestruturada, tendo como base os encontros e os dados levantados, foi iniciada a construção do jogo proposto, denominado "Trilha Empreendedora".

\section{Realização dos encontros}

Os encontros realizados tinham o objetivo de disseminar a cultura empreendedora e contribuir para o desenvolvimento de perfil empreendedor no grupo voluntário. A partir das intervenções se tornou possível identificar quais eram os níveis de conhecimento acerca do tema proposto, antes e após os encontros. Com o auxílio de metodologias ativas, que visam promover uma aprendizagem significativa no grupo de estudantes, aliadas às tecnologias, verificou-se a evolução no entendimento de conceitos e atitudes empreendedoras.

De acordo com as informações pesquisadas e coletadas foi possível desenvolver um cronograma para orientar as atividades a serem realizadas em cada um dos dez encontros previstos, conforme quadro 2 .

Quadro 2: Cronograma de encontros

\begin{tabular}{|c|c|c|}
\hline \multicolumn{3}{|c|}{ CRONOGRAMA DE ENCONTROS } \\
\hline ENC. & TEMA & AÇÕES \\
\hline 01 & $\begin{array}{l}\text { Diagnóstico inicial e } \\
\text { introdução ao } \\
\text { empreendedorismo. }\end{array}$ & $\begin{array}{l}\text { 1-Questionário Inicial; } \\
2 \text { - Quiz: Mitos e verdades (Kahoot!); } \\
3 \text { - Questionamentos e discussões. }\end{array}$ \\
\hline 02 & $\begin{array}{l}\text { Características } \\
\text { empreendedoras }\end{array}$ & $\begin{array}{l}\text { 1- Caça Palavras: Características; } \\
2 \text { - Discussões sobre a atividade; } \\
\text { 3- Dinâmica: A maior torre do mundo; } \\
\text { 4- Discussão sobre a dinâmica; } \\
\text { 5 - Leitura do texto e reflexão. }\end{array}$ \\
\hline 03 & $\begin{array}{l}\text { Empreendedorismo e } \\
\text { sociedade } \\
\text { (empreendedorismo } \\
\text { social) }\end{array}$ & $\begin{array}{l}\text { 1- Revisão encontro anterior; } \\
2 \text { - Leitura de texto e reflexão; } \\
\text { 3-Vídeos; } \\
\text { 4- Dinâmica: Empreendedorismo Social; } \\
5 \text { - Discussões sobre a dinâmica. }\end{array}$ \\
\hline 04 & $\begin{array}{c}\text { Liderança e trabalho em } \\
\text { equipe }\end{array}$ & $\begin{array}{l}\text { 1- Dinâmica: Campo minado; } \\
\text { 2- Dinâmica: Nó humano; } \\
3 \text { - Discussão sobre as dinâmicas; } \\
4 \text { - Criar definição de liderança e compartilhar no grupo } \\
\text { WhatsApp; } \\
5 \text { - Teste online; } \\
6 \text { - Discussões finais. }\end{array}$ \\
\hline & & $\begin{array}{l}\text { 1- Dinâmica: Comunicação; } \\
2 \text { - Vídeos; }\end{array}$ \\
\hline
\end{tabular}




\begin{tabular}{|c|c|c|}
\hline 05 & $\begin{array}{l}\text { Habilidade de } \\
\text { comunicação }\end{array}$ & $\begin{array}{l}\text { 3- Questionamentos e discussões; } \\
4 \text { - Dinâmica: Apresentação; } \\
5 \text { - Discussões finais. }\end{array}$ \\
\hline 06 & Criatividade e inovação & $\begin{array}{l}\text { 1- Visita técnica: Intereventos; } \\
2 \text { - Discussão sobre a visita; } \\
4 \text { - Leitura texto e análise; } \\
\text { 5- Dinâmica: Super-herói; } \\
6 \text { - Discussões finais. }\end{array}$ \\
\hline 07 & $\begin{array}{l}\text { Autoconfiança, } \\
\text { motivação, entusiasmo, } \\
\text { persistência e otimismo }\end{array}$ & $\begin{array}{l}\text { 1- Dinâmica: Topa ou não topa; } \\
2 \text { - Discussão sobre a dinâmica; } \\
3 \text { - Pesquisa online: Exemplos; } \\
4 \text { - Apresentação pesquisa e discussão; } \\
\text { 5- Dinâmica: Medos, superação e sonhos; } \\
6 \text { - Discussões finais. }\end{array}$ \\
\hline 08 & $\begin{array}{l}\text { Iniciativa, decisão e } \\
\text { responsabilidade }\end{array}$ & $\begin{array}{l}\text { 1- Vídeo: Day } 1 ; \\
2 \text { - Análise interativa: mentimeter; } \\
3 \text { - Discussões finais. }\end{array}$ \\
\hline 09 & $\begin{array}{c}\text { Aceitação de riscos sem } \\
\text { temor do fracasso e } \\
\text { rejeição }\end{array}$ & $\begin{array}{l}\text { 1- Dinâmica: Vida empresarial; } \\
2 \text { - Vídeos; } \\
3 \text { - Análise interativa: mentimeter; } \\
4 \text { - Discussões finais. }\end{array}$ \\
\hline 10 & Visão de futuro & $\begin{array}{l}\text { 1- Dinâmica: visão de futuro; } \\
2 \text { - Socialização da Dinâmica; } \\
\text { 3- Dinâmica: Análise de metas; } \\
4 \text { - Leitura de texto e análise; } \\
5 \text { - Discussões finais e encerramento. }\end{array}$ \\
\hline
\end{tabular}

Fonte: autores (2020).

A partir da definição do cronograma acima, em cada encontro com base em um tema gerador, as ações foram desenvolvidas buscando trabalhar de maneira interativa conceitos e características empreendedoras, e a utilização de ferramentas tecnológicas se fez constante, atraindo, motivando e instigando a participação dos alunos.

O primeiro encontro visou realizar o diagnóstico inicial e introduzir o tema "empreendedorismo", questionando os jovens sobre o que isso significava para eles. Na oportunidade foi realizado um quiz na plataforma Kahoot! sobre mitos e verdades do empreendedorismo, o qual se mostrou atrativo, bem aceito e acabou por motivar a participação e engajamento dos alunos.

O segundo encontro abordou de maneira geral as características empreendedoras. Pode-se destacar a dinâmica realizada que evidenciou a importância do trabalho em equipe, da liderança, motivação, engajamento, organização, planejamento, dentre outras características. Os alunos se mostraram desafiados e reagiram positivamente diante das propostas apresentadas. 
No terceiro momento, quando abordado o tema "empreendedorismo social", os alunos ficaram interessados pelo assunto proposto, após assistirem alguns vídeos selecionados, e realizarem uma dinâmica baseada na proposição de um negócio com viés social, os alunos debateram sobre o que haviam aprendido.

O quarto encontro baseou-se no desenvolvimento da liderança e do trabalho em equipe. Nas dinâmicas realizadas pôde-se perceber a participação e o comprometimento do grupo. As ferramentas tecnológicas presentes nesta ocasião se destacaram pelo uso do WhatsApp no processo de criação e compartilhamento de conceitos, e na utilização da web para a realização de testes online sobre liderança.

No quinto encontro foi abordado o tema "habilidade de comunicação", e foram realizadas dinâmicas que incentivaram o processo comunicativo entre os alunos. Também houve a utilização de vídeos para conceituação e exemplificação.

O sexto encontro foi marcado pela discussão sobre criatividade e inovação, houve a oportunidade de realizar uma visita técnica que ocorreu pela participação de um evento de empreendedorismo na própria escola, fomentando as discussões e análises pois aproximou os conceitos da realidade dos alunos.

No sétimo encontro o tema foi autoconfiança, motivação, entusiasmo, persistência e otimismo. Dinâmicas envolvendo autoconfiança e superação foram realizadas, a pesquisa incentivou os alunos a encontrarem e socializarem personalidades que fossem exemplos de superação.

O oitavo encontro trabalhou a iniciativa, a decisão e a responsabilidade, e, para isso, houve a utilização vídeos para a contextualização. Também pôde ser realizada uma análise interativa com apoio do site mentimeter, uma ferramenta que possibilita a interação online a partir da utilização do celular para responder enquetes, questionamentos, quizzes entre outras possibilidades.

O nono encontro se estabeleceu a partir da proposição de uma dinâmica sobre aceitação de riscos sem temor do fracasso e rejeição. Vídeos foram compartilhados e o mentímeter auxiliou na mediação do debate, já a dinâmica que simulou o cotidiano empresarial se mostrou como efetiva para a reflexão.

No décimo e último encontro foi abordado a visão de futuro, propondo aos alunos que prospectassem seus futuros e refletissem sobre suas metas e objetivos.

Após a realização de todos os encontros, com o apoio de ferramentas tecnológicas, dinâmicas, leituras, discussões e reflexões, foi realizada individualmente uma entrevista semiestruturada visando comparar o entendimento dos alunos em relação ao empreendedorismo, antes e depois dos encontros.

Foi possível constatar a partir dos feedbacks dos participantes que as metodologias ativas e a utilização de tecnologias contribuíram efetivamente no processo de ensino e aprendizagem, pois, de acordo com os relatos, houve um diferenciador em relação às aulas tradicionais, tendo em vista o incentivo a engajar-se, a participar com a turma e a refletir sobre os temas propostos, o que se mostrou significativo. Outro elemento que chamou a atenção foi o desinteresse inicial por parte de muitos alunos, mas que com o passar dos encontros foram se identificando e se dedicando no processo, mostrando que esta foi uma experiência relevante para o seu processo formativo. 
Desta forma, fazendo um paralelo com o questionário inicial, pode-se perceber que foi possível atingir os objetivos e anseios, em grande parte, apresentados pelos alunos.

Por fim, foi identificado também que muitos alunos foram capazes de fazer um comparativo em relação ao empreendedorismo e a sua vida pessoal e profissional, sendo capazes de visualizar as características empreendedoras como elementos presentes em diversas situações de suas vidas.

\section{Criação do jogo educacional}

O Jogo educacional desenvolvido se caracteriza como um jogo computacional, o qual tem por objetivo contribuir com o processo de ensino e aprendizagem de uma maneira diferenciada a partir da gamificação.

O jogo denominado "Trilha empreendedora", está diretamente relacionado ao empreendedorismo e ao desenvolvimento de suas principais características, tendo como objetivo contribuir com a formação do indivíduo de uma forma mais abrangente, sendo capaz de integrar conhecimentos de áreas específicas com conhecimentos cotidianos. E, assim, gerar novos conhecimentos, possibilitando uma visão ampliada do meio em que se está inserido, permitindo identificar oportunidades e empreender sobre elas. O jogo atua como uma ferramenta complementar nesse processo, contribuindo com as demais ações desenvolvidas ao longo do estudo.

O jogo apresenta questões relacionadas ao empreendedorismo e aos assuntos abordados no desenvolvimento da pesquisa, principalmente, no que tange ao perfil empreendedor. Desta forma, a elaboração dos questionários, a realização dos encontros temáticos e a aplicação das entrevistas semiestruturadas serviram como base para a definição das dez perguntas presentes no jogo proposto. Dessas, algumas foram retiradas da internet e adaptadas, enquanto outras foram elaboradas pelo autor.

Figura 1: Jogo educacional

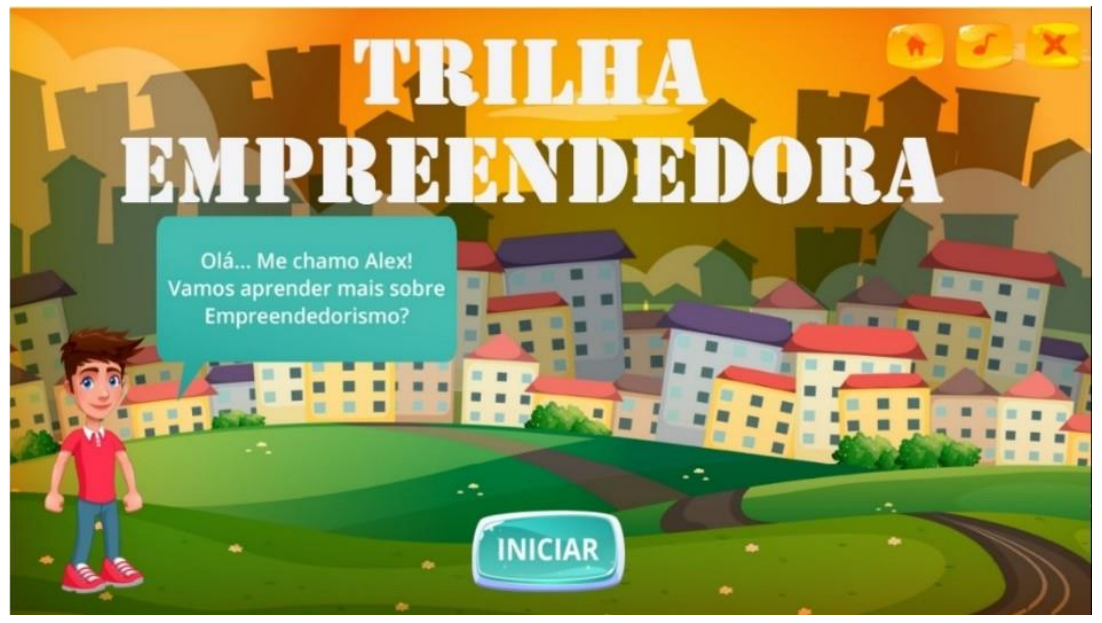

Fonte: autoria própria (2020).

\section{Considerações finais}


A realização deste estudo permitiu visualizar a importância do fomento da cultura empreendedora nos mais diversos espaços sociais, dentre esses, o ambiente escolar. Uma vez que, é a partir de contatos e interações, como a proposta por este estudo, que os jovens poderão, cada vez mais cedo, apropriar-se de conceitos empreendedores e desenvolver suas respectivas características, que os auxiliarão em todas as etapas de suas vidas, tanto no contexto pessoal quanto profissional, permitindo-os empreender em qualquer situação, além de estarem aptos para contribuir de maneira efetiva no processo de desenvolvimento social.

O estudo buscou articular e mobilizar conhecimentos que permitissem verificar os elementos pertinentes, para que se tornasse possível contribuir para o desenvolvimento da capacidade de empreender nas mais diversas áreas do saber a partir do fomento de características empreendedoras em jovens do ensino médio com o auxílio de ferramentas tecnológicas.

A partir do levantamento bibliográfico no qual foi possível identificar que os elementos do empreendedorismo podem e devem ser ensinados e aprendidos por qualquer pessoa, quebrando assim as barreiras do que se acreditava no passado, de que algumas pessoas estariam predestinadas a serem empreendedoras enquanto outras deveriam apenas segui-las. Pôde-se verificar a potencialidade do ensino de empreendedorismo, inclusive nos ambientes escolares.

No que tange à aplicação de ferramentas tecnológicas (TICS) e metodológicas no processo de ensino e aprendizagem relacionados ao empreendedorismo, como resultado, foi possível validar a significativa participação de ferramentas tecnológicas, tais como: internet, softwares específicos, redes sociais, vídeos, jogos e diversas outras possibilidades, assim como as metodologias diferenciadas, como as ativas, no processo de ensino e aprendizagem. Conforme relatado pelos participantes, os momentos em que foram utilizadas TIC's e metodologias ativas, foram os que mais Ihe chamaram a atenção e os impeliram a se engajar no processo de forma efetiva. Assim, constata-se a positiva inserção destes elementos.

Em relação à validação das contribuições da inserção do empreendedorismo no ambiente escolar, a mesma se concretizou a partir da análise das entrevistas semiestruturadas, mostrando que os encontros temáticos se apresentaram como efetivos no processo. Favorecendo assim o desenvolvimento do perfil empreendedor e a disseminação da cultura empreendedora, possibilitando e potencializando o desenvolvimento pessoal dos participantes e contribuindo para o desenvolvimento social.

Diante dos pontos apresentados, pode-se concluir que, auxiliados por ferramentas tecnológicas e metodologias diferenciadas, o objetivo foi atingido, embora com um número reduzido de participantes, apresentou ser uma contribuição efetiva no processo de desenvolvimento das capacidades e características empreendedoras nos jovens alunos do ensino médio.

No que diz respeito ao desenvolvimento de uma ferramenta tecnológica capaz de contribuir com o ensino e aprendizagem do empreendedorismo, é possível salientar o desafio na construção de um jogo que pudesse servir como uma ferramenta complementar de ensino de empreendedorismo. A partir de conhecimentos prévios e dados coletados no processo de intervenção pode-se desenvolver a "Trilha Empreendedora" que tem potencial para contribuir de maneira significativa no processo de ensino e aprendizagem de empreendedorismo. 
Por fim, vale destacar que este é apenas um possível primeiro passo, que muito ainda tem que ser feito para que a cultura empreendedora se estabeleça significativamente em nossa sociedade. Espera-se que esse estudo possa contribuir de maneira efetiva para o desenvolvimento e disseminação da cultura empreendedora nos ambientes escolares e nas mais diversas áreas do saber. E, portanto, que contribua com o desenvolvimento individual da capacidade dos jovens em procurar e identificar novas oportunidades e empreender sobre elas, tendo em vista, além do crescimento pessoal, também o crescimento social, pois, a partir de ações que visem contribuir com a comunidade local, todos irão se beneficiar das atividades empreendedoras executadas buscando a inovação.

\section{Referências}

ALVES, F. Gamification - como criar experiências de aprendizagem engajadoras. 2. ed. São Paulo: DVS Editora, 2015.

ANASTASIOU, L. G. C.; ALVES, L. P. Processos de ensinagem na universidade: pressupostos para as estratégias de trabalho em aula. Joinville, 2009. Disponível em:

https://edisciplinas.usp.br/pluginfile.php/4101112/mod_resource/content/1/Anastasi ou_Alves_Processos\%20de\%20Ensinagem.pdf. Acesso em: 08 maio 2021.

AVENI, A.; MELLO, A. S. Empreendedorismo para Crianças e Adolescentes no Brasil: comparação de métodos. Cadernos de Prospecção, v. 12, n. 1, p. 2-14, 2019.

CAUTHIER, F. A. O; MACEDO, M; LABIAK, S. J. Empreendedorismo. Curitiba: Editora do Livro Técnico, 2010.

CHIAVENATO, I. Empreendedorismo: Dando asas ao espírito empreendedor. 4. ed. Barueri: Manole, 2012.

DOLABELA, F. O segredo de Luísa. 3. ed. São Paulo: Cultura, 2006.

DOLABELA, F. Oficina do empreendedor. Rio de Janeiro: Sextante, 2008.

DOLABELA, F. Por dentro do universo empreendedor: Lições essenciais para transformar sua ideia em negócio. São Paulo: Saraiva, 2015.

DORNELAS, J. C. A. Empreendedorismo: Transformando ideias em negócios. 6. ed. São Paulo: Empreende/Atlas, 2017.

FERNANDES, N. P. et al. Quem é o empreendedor? a busca por uma definição do conceito através da produção científica brasileira. Revista Brasileira de Gestão e Inovação (Brazilian Journal of Management \& Innovation), v. 7, n. 3, p. 26-62, 2019.

FERRO, M. DA G. D.; PAIXÃO, M. S. S. L. Psicologia da aprendizagem:

Fundamentos teórico-metodológicos dos processos de construção do conhecimento. Teresina: EDUFPI, 2017.

FARDO, M. L. A gamificação como estratégia pedagógica: estudo de elementos dos games aplicados em processos de ensino e aprendizagem. Caxias do Sul: Universidade de Caxias do Sul - UCS, 3 jul. 2013.

GABRIEL, M. Educar: A revolução digital na educação. São Paulo: Saraiva, 2013. 
HASHIMOTO, M. Lições de Empreendedorismo. Barueri: Manole, 2009.

KAMPFF, A. J. C. Tecnologia da informação e comunicação na escola. 2. ed. Curitiba: IESDE Brasil, 2009.

LOPES, R. M. A.; LIMA, E. O.; NASSIF, V. M. J. Panorama sobre a Educação para o Empreendedorismo. In: LOPES, R. M. A. et. al. (Org.) Ensino de

Empreendedorismo no Brasil: Panorama, Tendências e Melhores Práticas. Rio de Janeiro: Alta Books, 2017.

MOREIRA, J. C. G.; LUDOVICO, F. M.; KAROLESKY, M. L. E. As Metodologias Ativas e Seus Atores Aprendentes. Revista Pleiade, v. 12, n. 25, p. 18-28, dez 2018.

NICOLETTI, A. A. M.; GUERRA FILHO, R. R. FILHO, R. Aprender brincando: a utlização de jogos, brinquedos e brincadeiras como recursos pedagógicos.

Revista de divulgação técnico-científica do ICPG, v. 2, n. 5, p. 91-94, abr/jun. 2004.

PELIZZARI, A. et al. Teoria da Aprendizagem Significativa Segundo Ausubel. Revista PEC, v. 2, n. 1, p. 37-42, jul/jun. 2002.

PEREIRA JUNIOR, Errol F. Z. Background do empreendedor: proposta e validação de um modelo. 2020. 132 f. Dissertação. Mestrado em Administração (Programa de Pós-graduação em Administração). Universidade Federal do Rio Grande, 2020.

PRINCE, J. D. Gamification. Journal of Electronic Resources in Medical Libraries, v. 10, n. 3, p. 162-169, jul. 2013.

ROJAS, R. S. B.; MONICH, A. E.; LEZANA, Á. G. Avaliação da efetividade de um programa de empreendedorismo no ensino fundamental. XXX Encontro Nacional de Engenharia de Produção - Maturidade e desafios da Engenharia de Produção: competitividade das empresas, condições de trabalho, meio ambiente, n. 30, p. 13, 2010. Disponível em: http://www.abepro.org.br/biblioteca/enegep2010_tn_stp_133_848_16667.pdf . Acesso em: 25 jun. 2021.

SANTOS, R. V. Abordagens do processo de ensino e aprendizagem. Integração, n. 40, p. 19-31, jan/mar. 2005.

SALIM, C. S; SILVA, N. C. Introdução ao empreendedorismo: Despertando a atitude empreendedora. Rio de Janeiro: Elsevier, 2010.

SIGNORI, G.; GUIMARÃES, J. C. F. DE. Gamificação Como Método De Ensino Inovador. International Journal on Active Learning, v. 1, n. 1, 2016.

VIANNA, Y. et al. Gamification, Inc. 1. ed. Rio de Janeiro: MJV Press, 2013. v. 53. 
Recebido: $11 / 11 / 2020$

Aprovado: 18/09/2021

Como citar: STOCHERO, A. D.; FRANZIN, R. F. O desenvolvimento de competências

empreendedoras em alunos do ensino médio a partir da utilização de metodologias diferenciadas

e ferramentas tecnológicas. Educitec - Revista de Estudos e Pesquisas sobre Ensino

Tecnológico, v. 7, e155221, 2021.

Contribuição de autoria:

Anderson Daniel Stochero: Conceituação, curadoria de dados, análise formal, investigação, metodologia, administração de projeto, software, supervisão, escrita (rascunho original) e escrita (revisão e edição).

Rozelaine de Fatima Franzin: Conceituação, curadoria de dados, análise formal, investigação, metodologia, administração de projeto, software, recursos, supervisão, validação, visualização, escrita (rascunho original) e escrita (revisão e edição).

Direito autoral: Este artigo está licenciado sob os termos da Licença Creative CommonsAtribuição 4.0 Internacional. 